\title{
Program Intervention in the Process of Cultural Integration: The Example of French Practicum
}

\author{
J o h n E ng l e \\ American University Center of Provence \\ Université de Toulon et du Var
}

\section{Lilli Engle}

American University Center of Provence

\section{Introduction}

One thing that strikes foreign visitors to US colleges and universities is the completeness unto itself of American campus life. While this impression is clearer in a small college town than in urban universities dispersed in their cityscapes, certain characteristics consistently reinforce a sense of the college's self-sufficient disconnection from the surrounding environment. We see this in things like round-the-clock access to library stacks or computer banks, idyllic landscaping, an air of security behind the town-gown demarcation line, and the easy on-campus availability of leisure activities as well as all essential (and many non-essential) products and services.

Appropriate as such a setting may be for research or the pure concentration of intellectual energy, its separation from real life and the world students are preparing to face is patent. This is still the impression most colleges give, and this despite the fact that, in recent decades, the story of American undergraduate higher education has in part been that of increasing efforts to link the academy with the larger world. Community outreach programs, now-common scientific field work, internships, Washington semesters, and, of course, international education head a list 
of activities intended to forge meaningful links between the educational experience and the physical, economic, and social conditions of a world which, to many in the campus stockade, must still seem more virtual than real.

In these pages, the positive contributions of international education need little justification. Leaving aside the abundant political or economic arguments for overseas study to focus upon its role in a liberal arts education, study outside one's own culture can force the maturing individual to confront elemental human questions regarding the individual and the group, the present and the past, me and the other, my truth or another's. For centuries gypsy scholars have found education in a foreign setting a powerful stimulus to the very questioning and search for meaning that is, or should be, at the heart of liberal education.

We can, we think, advance the premise that study abroad enriches to the degree that it takes participants out of the velour world of the campus and the form-fitting comfort of their own culture-in other words, to the degree that it disturbs and, thus, awakens. As anyone who has lived abroad knows, the genuine traversal into another culture is a challenging, occasionally painful experience. Yet it is primarily through the temporary discomfort of challenges met, the hard learning of embarrassment, and the humility fostered by intimate contact with other ways of thinking and being that education occurs abroad. We might say that it is only in this discomfort that ease and security abroad can take root.

Structuring student programs abroad, we err in duplicating the comfortable isolation of the campus. In practical terms, such isolation begins with the illusion that low levels of host language proficiency suffice and the seemingly innocuous reassurance of organized group travel. It intensifies over time with instruction in English or by non-native instructors, large numbers of US students together, housing apart from the community or with American roommates, the e-mail equipped haven of a student lounge, and so forth. Most anyone faced with a new culture will perceive it in many ways as "hostile." Certain extremely confident and outgoing twenty year olds will quickly outgrow the overseas program security blanket and directly take on the challenge of a new, at times "hostile" culture, but the tendency of most, at least in the early phases of their stay, is to bundle up and seek refuge in the familiar.

Such a reaction shouldn't elicit moralistic disapproval; it is natural, and we ignore or dismiss it at our peril. In designing study abroad pro- 
grams, professionals should consider forms of defensive grouping simply the terrain upon which they are required to build. Given this baseline, students' tendency to retreat from the very culture they came to at often great sacrifice, how then are we to help create a true cultural interface? How can we tease into being the appropriate conditions for the cultural meetings or interactions or confrontations that constitute the special contribution of international education?

\section{Towards French Practicum}

These were the questions on our minds several years ago when we accepted the challenge of helping to create an undergraduate study program in France. With over one hundred French programs officially listed in the professional guides, there seemed little reason to do so if the new program did not in some original fashion energetically facilitate the cultural integration of its participants and thus address the weakness we perceived in much of study abroad. The challenge was to link a program of rigorous, culturally relevant course work to mechanisms that would incite rapid, authentic contact with the host culture not just for the outgoingwho need little help—but for the full range of program participants.

The result of this reflection was a philosophy informing all aspects of program organization and, more concretely, a mandatory core course called French Practicum (see course outline in Appendix). Before turning to a presentation of program organization and results, however, it is appropriate to address an important issue, that of scientific method and data now playing a growing role in attempts to structure our understanding of the dynamics of international education. Like the brief analysis of study abroad needs above, the remarks to follow are admittedly based less upon social science research methods than upon the collective experience of nearly twenty years of on-site overseas program direction. They draw upon personal dealings with over 2,500 semester- and year-abroad students from hundreds of different home institutions, including countless conversations, letters, complaints, program evaluation forms, and periods of observation. They reflect years of exchange with home university professors, colleagues coordinating study abroad stateside, and those in similar positions abroad, as well as access through extensive French university teaching experience to the comparative reactions of dozens of European 
ERASMUS and other study abroad participants.

Before taking on our current positions, we worked with a large institution receiving up to 500 students yearly for full-year, semester, and summer terms. Students varied in language proficiency from no prior French through advanced level. Compared to that of the dozen or so other programs in the French provinces or Paris that we have come to know fairly well through contact with their administration and students, the student group was similar, and the institutional commitment to local cultural contact visible in such program elements as local homestays or direct university enrollment was roughly average.

Perhaps our most common and frustrating personal experience as program administrators was that of a recurring dissonance, namely that between what most students say they want to do abroad and what they actually tend to do once there. Repeatedly claiming in application form personal essays that they wish to speak French and "live" their host culture, many-including, surprisingly, those best equipped linguistically for the experience - act abroad like what they really want is the familiar comfort of the home campus. Under the pressures of cultural adaptation, a hunger, sometimes expressed, often inchoate, to draw personal meaning from life abroad, to meld that life intellectually and emotionally into a student's own life story, often devolves into the thoughtless consumption of sights and the reduction of experience to entertainment.

In designing the new program, we found that a surprisingly direct route out of this dispiriting paradox might be simply to take students at their word. Why not accept a fund of pre-departure good will as honest and profoundly motivated, then hold students to their own good intentions, to their own high standards? In other words, if students wanted to interact with the host culture, they would have that interaction: it would be part of the program. At this point were born two guiding principles: 1) active program intervention in the process of cultural integration would be necessary; and 2) program mechanisms directed towards this cultural integration must be mandatory. Reflective engagement with the home culture would not be an option, but a requirement. 


\section{French Practicum: A Required Core Course}

While this commitment would condition all aspects of program design, the structure chosen for active intervention in the integration process soon became that of an obligatory, credit-bearing core course providing forms of direct contact with the French and their culture while creating formalized opportunities for reflection. We felt that, especially in the crucial and difficult first weeks abroad, students needed a structure that, while imposed, nevertheless only imposed compliance with practices consistent with what most claim are their own personal goals. Attaching academic credit to the core course would give it a necessary legitimacy while concretely communicating the message that, particularly abroad, curriculum and extracurriculum are intimately linked.

The course as finally designed was called French Practicum to highlight its component of experiential learning. Like a teacher's or clinician's practicum, it serves students of French language and culture as a "supervised practical application ... of previously studied theory" (Webster's Ninth New Collegiate Dictionary). It is important to restate that the mise en pratique of years of classroom learning through a required sequence of contact opportunities in the local French community is only part of the story. An essential complement is the filtration and evaluation of this experience in weekly course meetings focusing upon cultural difference, the varied processes of culture crossing, and relevant aspects of contemporary French life and customs. Like the study abroad experience itself, French Practicum thus takes place both in the streets and the classroom.

\section{Context}

Before a presentation of French Practicum organization and particulars, it is important first to understand its context, a small (25-35 students) independent semester and academic year program for "advanced" level students in French from differing home universities with which credit transfer is arranged directly. All program participants take French Practicum within a course load consisting of an average of four other courses organized on-site (French literature, art history, etc.) as well as one course by direct enrollment at the French university. All students are 
housed in single-student homestays with French families.

\section{Course Organization}

To repeat, the two complementary elements of French Practicum are a) a program of required activities placing students into meaningful contact with the local French population; and

b) a weekly two hour classroom meeting devoted to reflection and analysis.

(a) Experiential Requirements: Authentic Local

\section{Contact}

For successful completion of this aspect of French Practicum, all program participants engage in the following activities:

1) Linguistic component: at least two hours weekly of conversation exchange with a French learner of English (one hour French, one hour English)

2) Personal interest component: pursuit of a personal interest or hobby through membership and regular participation in a club, organization, team, choir; enrollment in lessons; etc.

3) Community service component: at least two hours weekly of local volunteer work

These requirements equal a commitment of approximately six hours weekly. The goal is to provoke significant opportunities for cross-cultural interaction but to do so while allowing sufficient time for traditional academic work and "independent" cultural discovery and reflection. On at least three separate occasions per week students are thus required to venture forth into situations making differing cultural and linguistic demands upon them and placing them in interaction with different groups or individuals from the host community. Such contacts are intended to initiate relationships and opportunities for cooperation upon which further personal exploration can be centered.

The activities required for French Practicum are chosen with care to create "natural" meeting sites and provoke interactions which are mutually beneficial for all participants and thus likely to continue. The first, conversation exchange in the linguistic component, is a classic mechanism 
abroad for the efficiency with which it draws together individuals with complementary needs. When conversation partners are young people, ideally university students, the program also serves as an indispensable introduction into the local scene. In pairing partners, it is important to respect individual preference on both sides as expressed in a pre-selection interview or information form, for the durability of this contact is closely linked to personal chemistry.

The personal interest component calls upon personal hobbies or avocations likely to act as a bridge into French culture. Chess, yoga, singing in a chorus, playing European or American football, returning to the piano one abandoned at twelve : interests such as these introduce students to like-minded individuals, thus sidestepping certain cultural barriers. Within the nurturing regularity of training sessions, club meetings, or weekly lessons, shared interest acts as a first step towards meaningful interaction across cultural lines. Furthermore, the pursuit abroad of a long-standing personal interest reminds students that time spent in the host culture is not a detached parenthesis but part of the continuum that is their lives.

With the community service component students are again given room for individual preference within a guiding framework. At least two hours each week they are required in effect to drop what they are doing for themselves and focus upon the needs of others. One particularly difficult challenge is to find personally and culturally acceptable forms of volunteer service in which students, limited by their relative youth and imperfect command of the language, can provide aid that will be perceived by all parties involved as worthwhile. In France, over time we have found that child care and kindergarten assistantships, the musical animation of hospital pediatric groups, serving at soup kitchens for the homeless, and offering companionship and conversation to the aged tend to be appropriate choices.

(b) Weekly Class Sessions: Reflection and Analysis

In addition to required extramural activities, students meet once weekly for a two hour classroom session. Extending the normal program model of frontloaded orientation, these meetings function as a kind of 
continuing term-long cultural orientation, a regular debriefing that evolves in its focus just as the students and their perceptions of their experience evolve. Its goal is to enrich and extend authentic cultural experience through reflection, personal articulation, and practical advice, and to encourage overall intellectual development through rigorous written and in-class analysis and frequent feedback. The choice of a single two-hour session is a compromise ideally providing sufficient time to explore certain issues in depth while allowing students to complete already very busy schedules with, one would hope, ample opportunity as well for moments of reflective solitude.

In the first semesters after French Practicum was put in place, classroom sessions took place largely in English for the first several weeks of a term, even though program participants all had a relatively high French level. During this difficult period of early linguistic and cultural adaptation, we felt it was important both that information imparted be precisely understood and that these meetings offer a genuine forum for the subtle expression of thoughts and emotion more likely to occur in one's native language. We have recently done the course in French from Day 1, however, and can say that the "good example" of consistent French speaking more than compensates for what little is lost in terms of accuracy.

Because the "subject" of these meetings is the seamless whole of a student's experience abroad, sessions retain a necessarily improvisatory quality. Students use this forum to pose questions regarding cultural usage, explore recurring homestay tensions, or discuss evolving news stories. Yet within a format encouraging spontaneity, each meeting is nevertheless organized by theme and prepared with a reading or video assignment. Though not a French Civilization class, an effort is made to treat those subjects most likely to open students as quickly as possible to the French-speaking and -thinking world around them (for example, the nearobsession in France today with questions of immigration and integration). Occasional local guests - a member of the city council, a longtime expatriate, a high school teacher-share their concerns and experiences with students. Framing the transmission of raw cultural information, the course aims as well to heighten students' awareness of the acculturation process they are undergoing by familiarizing them with the conceptual language of cross-cultural encounters.

In class, while any subject is fair game, a general progression of pre- 
pared topics leads from the prescriptive and immediately "useful" towards broader and more abstract principles regarding cultural difference. Three days after students' arrival, if a group leader evoked differences in the French sense of private space, this would be unremembered or at least unassimilated theory. Six weeks later, what might have been mistrusted as theoretical becomes a discussion of telling personal urgency. Only a month or two along do students begin to accumulate a base of overseas experience and confidence adequate to move beyond the immediately pragmatic to the meaningful assimilation of concepts like the flexibility of time, the "personal bubble," or "high context" communication. Always eager to discuss their experience, they then take avidly to such principles and language.

Assignments, readings, and other preparation are chosen to heighten insightful personal examination of the cultural experience students are undergoing. Several days before each session, they turn in written reports in French on their performance in each experiential component of the course (linguistic, personal interest, community service) as well as on their attendance at their French university course. While a certain number at each class meeting prepare brief oral reports on announced themes, all students are required to articulate in approximately 300 words at least one weekly découverte culturelle, or cultural discovery. An abbreviated form of journaling, this personal writing provides training in the observation and description of cultural traits. Students are encouraged to speculate analytically upon root causes for the differences noted while avoiding the trap of value judgments.

Pragmatic in its emphasis upon rapid cultural insertion (and complementing the "high culture" bias of the main body of student academic work), class sessions have a tendency to stress everyday usage and popular culture as a repository of cultural impulses as well as a comparative approach based on correspondences with American culture. The goal is as seemingly superficial as giving twenty year olds something to talk about when they go out with French peers. The real agenda is helping students to link their individual cultural discovery both backward, into the fund of a personal past and its cultural conditioning, and forward, into a new, internationalizing self. 


\section{Academic Credit and Evaluation}

On the grade report to home universities, French Practicum represents two semester credit hours and is marked on a pass/fail basis; when home schools request letter grades, they are provided. No unexcused course meeting absences are allowed, and students are required to justify in writing any non-performance of experiential activities. Even without the "stick" of traditional letter grading, students nearly always perform their external activities regularly and tend to arrive at course sessions with a fairly high level of preparation. Remarkably, this is true too of the one student in eight whose home university, suspicious as some are of experiential learning, refuses to grant transfer credit for this unusual course. We credit this good will in part to a continuing effort to present French Practicum as a key, unifying element of students' experience and what sets it apart from that of many others.

Ideally, assigning French Practicum two-thirds credit weight with grading on a pass-fail basis retains enough administrative heft for the course to be taken seriously by students but not so much as to weigh them down in what should be the play of cross-cultural interaction. Yet this kind of administrative middle ground understandably makes certain home universities uncomfortable. It is with this difficulty in mind that we recently decided to offer students and their home institutions the formal choice between the course as traditionally offered (P/F, two credit hours) and a version with full three credit academic weight and letter grading requiring an increased traditionally "academic" work load (notably, a long personalized cultural research project in French analyzing an aspect of French culture or specific cultural "scene").

\section{Organizational Challenges}

The extremely work-intensive nature of French Practicum imposes strains upon on-site organizers. While there are sizable demands upon the in-class instructor, the main difficulties of organization lie in its experiential components. The placement of students in each experiential component requires extensive pre-arrival preparation: the recruiting, interviewing, and orientation of appropriate conversation partners; the maintenance of current information regarding likely club, team, or hobby 
choices; and, most burdensome, the forging of strong prior contacts for community service opportunities. In France, with its highly developed public sector and administrative layerings sometimes impeding access to private volunteer work opportunities, this bridge-building can be especially trying.

On the arrival of students, program administrators race the clock. Students need to be oriented and directed towards opportunities such as community service quickly. Not only does this provide them with the reassuring focus of a busy schedule in the disorienting first days abroad, it also taps into a fund of enthusiasm and good will that, if not, can too easily be squandered and replaced by comforting immersion in rapid, superficial bonding with other Americans, English-speaking hangouts, or the weekend train. During the initial orientation period, each student is privately interviewed, with frequent follow-ups, for the selection of experiential components. The administrator assigned this task is kept very busy finding time in student course schedules, setting up first meetings, and seeking new opportunities where needed.

A further responsibility is the preparation of conventions de stage, contracts signed by students and the directors of establishments where they are to perform their community service. A formal engagement in French, used generally with work place internships, the convention regulates liability questions but, more importantly, has a cultural legitimacy that encourages respect and signifies the importance attached by both the host society and the program to the contributions of students. It is as well an authentic host culture reminder that individual experience takes place in a context of interpersonal and intercultural accountability. Appropriate as it is, the now-traditional "language pledge" signed by American students abroad simply cannot throw the same kind of cultural weight behind its promise.

The creation of a program mechanism like French Practicum demands sufficient on-site personnel and would likely, in France at least, be limited to programs of small to medium size. While a large American study program could engage a staff capable of the extensive organization and necessary follow-up for, say, a hundred students or more per semester, such numbers would likely exceed the community service capacity of any French city short of Paris. Linked as such a program is to its immediate environment, local conditions must be taken into consideration at all moments in its organization. 


\section{Commitment, Not Consumption}

For French Practicum best to achieve its goals of increased student engagement with the local culture and heightened personal reflection regarding that experience, it is treated less as a "course" in the traditional sense of the term than as a key organizing element in the totality of a student's experience abroad. The commitments it embodies are echoed and amplified elsewhere throughout other aspects of program organization and administration. The lessons most clearly embodied by French Practicum are that cross-cultural encounters are more enriching when experienced on a personal level unbuffered by the security of the student group and that meaningful cultural experience is not "consumed" but earned by active personal commitment. In other words, no pain, no gain. This simple but essential message conditions nearly every aspect of the program.

In our first contacts with future students-who come from disparate home institutions and about whose pre-departure orientation it is difficult to generalize-we engage in an extensive information effort intended both to familiarize them with the particulars of French Practicum and prepare them to see themselves as engaged actors in the local scene and not as the student-tourists of which they have often heard. The application personal essay, for example, requires future participants to discuss the unusual nature of the course and their vision of how it will mesh with their prior and projected future experience. To administrators back home signing off on credit transfer, they are also frequently required to describe French Practicum and articulate its differences. Not surprisingly, when students arrive, most are well aware of the goals and methods of the core course and of the program philosophy it embodies

This awareness may also be the residue of certain clearly enunciated, somewhat unconventional program policies. To illustrate to students that they cannot make a full commitment to life abroad with one foot in their lives back home, for example, they are informed before arrival that e-mail will not be available for student use. The complementary message that participants will be encouraged throughout to leave their comforting peer group is made concrete by the conscious (and, again, clearly explained) decision not to offer any form of organized group travel to students. Participants are told that their commitment to cross cultural lines began 
the moment they chose to leave the safe comforts of campus and home to study abroad, and that they would be compromising their formal entry into that new culture through the bonding with other young Americans that occurs so quickly on a group flight. It is their personal responsibility, independent of the potential comforts of the student group and the aid of the program, to create their own experience.

Similar reinforcement of what will be another experiential lesson of French Practicum comes before their arrival when students are asked to indicate their housing preferences. Before the standard questions, no-nonsense statements address such issues as smoking, pets, or vegetarian and other special diets. To insist that, in France at least, an inflexible line on such questions will limit a student's choice of quality housing illustrates central truths about student life in a foreign culture : namely, that one cannot control one's environment as easily as one might be able to on the home campus and in the home culture, and that the essence of successful life abroad is learning the graceful bending of one's will, forged in a personal and cultural history, to other imperatives.

On arrival, the stress upon personal, unmediated access to French life continues when students are met at the airport not by program administrators and a chartered bus but directly and individually by their host families. The first welcoming faces that frightened, jet-lagged students see thus belong to members of the host culture. The one-student-per-family homestay, the only housing option, functions as further reinforcement of program goals. In the French home there is no temptation to speak English, no American roommate as cultural shield or filter. Student homestay orientation, returned to throughout the semester in Practicum class sessions, naturally focuses upon the insertion of the student into the daily give-and-take of household rhythms through regular participation in chores and the assumption of small responsibilities like walking small children to school or setting the dinner table.

With its sense of security and belonging earned by adaptability, understanding, and personal investment, the individual homestay ideally becomes a microcosm of the overall experience abroad. Since the construction of mutually rewarding homestay relationships is presented as a dual responsibility, families attend orientation sessions as well, including a clear explanation of program goals and the particulars of French Practicum. As hosts are often the single most important influence upon 
students abroad, it is vital to enlist their aid in encouraging students through word and deed to adopt behavior likely to favor their insertion within the family and, more largely, the local scene. On both sides, it is essential as well to decommercialize the student-host relationship so that students are less perceived—by families and by themselves—as boarders than as active participants in the lives of their hosts. While students are told that families receive an indemnity for their demi-pension housing, they do not know the figure, nor, unless the home institution specifically requests a breakdown, are overall program fees even divided into tuition, housing, or other categories.

In overseas program direction no more dreaded words exist than "I paid for that." A handy funnel for the vague and legion discomforts of culture shock, recourse to the consumer mentality indicates the superficial one-way relationship with the host culture of the amusement park-goer or shopper: with the individualistic near-future orientation of American culture a familiar spur forward, dropping that sight, this conversation, that city into the designer bag, then turning blithely to the next experience, and never looking back. Its opposite is an attitude ideally fostered by French Practicum, that meaningful overseas experience cannot be purchased or "done," but must be constructed through thoughtful individual commitment and the painstaking day-to-day work of interpersonal connection. Through community service and other voluntarily chosen obligations, students earn a sense of security, confidence, and belonging, along with heightened cultural literacy and sharpened linguistic skills. The guiding principle of French Practicum is that students are most free abroad when linked to a community through willingly accepted bonds of self-discipline, affection, and responsibility to others' needs.

With its dual focus upon cultural experience and reflection, French Practicum is intended to emphasize the holistic nature of the student's lived experience abroad. Students do not tick their way through a checklist of separate concepts or experiences ("culture shock," "the French professor's relationship with students"). They live a seamless whole of experiential learning in which homestay and classtime, personal and cultural history, sidewalk cafes and subjunctive errors, memory and desire circulate like air. Somewhere in that space in between, Practicum seeks ideally to play a unifying role, stimulating cultural contact then framing experience for thoughtful response, fortifying and refocusing students as they head 
back out towards the world. We think of French Practicum as a very modest version of the 19th century American university "capstone course." Called "moral philosophy" by Mark Hopkins and other practitioners for want of another term, it was a place where things could come together, an occasion for the weaving of the multiple strands of formal learning and past, present, and freshly imagined future experience.

\section{French Practicum: A Progress Report}

To this point, over one hundred and fifty students have participated in a French Practicum which has evolved slightly over time but which has retained its central commitments as described above. An evaluation of its relative success or failure in its mission takes into account program evaluations written by about two-thirds of that number, extensive discussion with students, letters from alumni, echoes from home school administrators and professors, and personal observation in the context of other student groups whose experience was unmarked by a such a program.

It is clear that the overall balance sheet is quite positive. Without doubt the high degree of student involvement in local life that we have observed is partly due to the fairly solid linguistic preparation of participants, the close personal contact and monitoring of a small program, and the self-selection of students, more than half of whom indicate in various ways that their program choice was based on French Practicum and specifically its community service component. That said, it is difficult to dissociate certain kinds of observed performance from a proactive core course common to all participants upon which much emphasis is placed before and during the student's experience abroad.

In terms of the experiential components of the course, our observations confirm students' written program commentary in which the community service commitment and regular conversation exchange are linked with individual homestays as leading factors in their involvement in the local community. With occasional exceptions-a rugby player on just the right team, a student who takes a leading role in a church choir, etc. - the personal interest component tends to incite somewhat less enthusiasm. If participation in one Practicum component flags over the term, it is likely to be in this area. Reasons for this may include insufficient preparation of students, inappropriate placement, or a barrier of cultural difference tak- 
ing the immediate fun out of a familiar leisure activity. We're tempted to see it as a question of mutual benefit. In conversation exchange the benefits for both parties are obvious, and in volunteer work the student provides needed help and is rewarded with the pleasure of being needed. These complementary benefits allow participants on both sides to clear cultural hurdles more easily, something not as apparent in the personal interest component.

Student enthusiasm for the other components is evident. Regarding the community service requirement : "some of my fondest memories, " "one of the easier ways to integrate because they really appreciate your presence," "a wonderful way to get in touch with the French community," "I learned a lot and it gave me a wonderful sense of pride and accomplishment sharing and helping others." Conversation exchange draws similar reactions, most notably a stress upon the first friendship as a doorway to others and the complementary nature of the exchange. "They were the easiest people to relate to," writes one student, "because they were learning English and knew how difficult learning a language can be."

Paired in the first week in a convivial setting, partners seem to play an even more important role in students' linkage with the local population than their direct university enrollment, in part because of the element of self-selection. Perhaps imagining future travel to the land of their new American friends (and Michael Jordan), French partners clearly find it in their interest to nourish and extend their social contacts with our students. From the start of the semester, we rarely see the latter in an Aix café without a French acquaintance, or, when students do group up on the weekend, it is almost always as part of a larger group including French students. This contact is further encouraged through the policy dictating that attendance at any program social gathering is contingent upon the student being accompanied by at least one French guest. The result is a level of regular host culture contact that, measured by observation and the sometimes self-satisfied reports of participants, seems to be far higher than that of the average American student abroad.

While students take enthusiastically to most of the roughly six hours of weekly extramural commitment required of them for French Practicum, the total effect can an times seem overly demanding. Some inevitably grouse about having to run about to satisfy the demands made upon them, yet even then this complaint is generally couched in appre- 
ciative terms. As one student from a small East Coast liberal arts college wrote, "they kept us busy, which I resented at times, but I really felt like I was living a 'real' life." This impression is comforting in that, while a certain amount of the meditative solitude which deepens cultural understanding is vital, one sub-goal of French Practicum is students' immersion in the comforting focus of a full schedule. As inappropriate as the maxim can be in other circumstances, an idle mind can be the devil's workshop in the tough first stage of a stay abroad. "We were gently forced," writes a woman student from a college in New York state, "when otherwise I probably would have crawled into my culture-shocked shell. " As simplistic as it might sound, we've noticed that a certain amount of necessary hustling about heads off some early problems of adaptation.

The in-class sessions of French Practicum seem also to serve as a filter for certain personal problems linked to cultural adjustment and first line of pressure release. The refocusing involved in each week's continuing orientation can head off culture clashes before they occur and air tensions that might otherwise go underground into complaints or rumors. Students take pleasure in the sharing of experiences and feelings, and the perverse and completely human reassurance that comes from knowing others are suffering too. Perhaps because French Practicum already intervenes so actively in the personal drama of cultural adaptation, we have noted a dramatic reduction in one-to-one troubleshooting on the part of the program administration. Several host families, experienced with students from other programs, have confirmed the relatively problem-free nature of students from this one. Again, while there are numerous explanations for this difference, we are tempted to see it at least partially in the context of a philosophical orientation symbolized by French Practicum, echoed in other aspects of the program, and accepted by students.

Perhaps the most striking embodiment of what we can only characterize as the course's success is the relative lack of weekend traveling on the part of students. In the past three semesters, for example, in groups of approximately 30 participants, to our knowledge only three or four students have left on overnight weekend travel before the mid-term break (and two of these cases involved travel either with a conversation partner or a "sibling" of the French host family). After the mid-semester vacation, traveling does increase for all students but in the vast majority of cases not to an excessive level, perhaps one to two weekends away in seven weeks. 
This is an extremely satisfying result to us as program administrators, representing as it does a comfort in and connection to the local scene. Willing to accept a central "constraint" of cultural involvement-very simply, if you want to get to know French students, you have to be free to get together with them on the weekend—students accept schedules including Friday class work with apparent equanimity. Again, this we credit at least partly to French Practicum and the philosophy it embodies.

\section{French Practicum: Looking Ahead}

French Practicum is an evolving experiment in active program intervention in one of the most challenging areas of study abroad. While it is clear to us that the course is a positive step towards more, and more thoughtful, cultural interaction for students abroad, it seems important now to apply forms of scientific method to study of the ends and means of Practicum and of other program mechanisms like it. The experience of one program, and particularly its future development, can only be enriched by the meaningful comparison (difficult as this is across such variables as student selection, program design, and cultural context) with the experience of other programs working towards deeper engagement in the host culture on the part of their students. As structures for such more systematic forms of information exchange and comparison develop, we welcome dialogue with other professionals seriously interested in this issue.

On a daily level in its small program context, French Practicum will no doubt continue to evolve in order better to fulfill its mission with regard to students and more satisfactorily respond to the needs of home institutions. In the experiential aspect of the course, for example, we return periodically to the possible adoption of the work internship-as distinct from the volunteer work requirement-as a logical next step in cultural insertion. While internships are tough to arrange in France and while their personally utilitarian nature seems partially at odds with current program emphasis upon commitment to the "giving" in the giveand-take of cultural exchange, the course may eventually evolve towards some modified form of local work experience for full-year students.

Other areas in which we are changing or have considered change are the in-class element and the component of personal writing structured to 
encourage in-depth analysis of cultural experience and personal growth. For the moment a moderate amount of regular writing (reports on experiential activities, the weekly Découverte Culturelle, etc.) and two hour classroom sessions encourage exploratory cultural/personal questioning and the formulation of tentative responses. As we mention above, we have also recently offered students the option of taking the course on a letter grade, three credit hour basis, with a complement of more academic writing, including a term-length cultural research project. In the two semesters this option has been available, though, only about $10 \%$ of students have chosen it. Speaking with them, we are convinced that this is less because they are shying away from an increased work load than because home university registrars don't really know what to make of an "experiential learning" course and are thus hesitant to sign off on one, especially one graced with a full credit load and traditional grading.

The future of the course may lie in greater collaboration with home universities to ensure acceptance of such full credit recommendation across the board. In practical terms, this would allow us to up the writing requirement and class time beyond what we can reasonably expect from students taking the course on a partial credit basis. The goal, of course : to heighten the analytical and reflective nature of the course and thus strengthen the link between authentic cultural experience and personal intellectual and emotional growth. Two possibilities for enhanced personal writing include the substantial individualized cultural research project (currently a part of the full-credit version of the course and now in use in other innovative overseas programs) and the creative use of regular personal journaling.

Both forms serve students by eliciting meditative reaction from the raw material of cross-cultural experience. The journal follows a continually advancing point of interaction amongst personal nostalgia, current foreign experience, and future projection, while the cultural research project examines a personally selected aspect of the host culture through the slow accretion of traditional and personal (interviews, observation, reactions) research. Their "autobiographical" and "ethnological" emphases might dovetail appropriately within a program structure like French Practicum, while offering responses to the need, sometimes expressed by home institutions, for an increased academic element and heavier home credit recommendation. Here as with any prospective changes, though, it must be 
asked whether possible course innovations like the journal, term-length project, or other options are culturally acceptable, fall within the capacity of the local community, and can be reasonably absorbed within a student's overall course load and personal schedule.

Such nuts-and-bolts changes are no doubt coming, and the course as it is taught today may have little superficial resemblance with what it will look like a decade from now. What will remain, we are certain, is the heart of the course, its resolute attempt, sometimes against long odds, to increase the quantity and improve the quality of its students' cross-cultural encounters. The major innovation of Practicum is the rendering of such experience and reflection upon that experience an obligatory and credit-bearing curricular component within an overall program structure turned unsparingly towards in-depth, non-tourist cultural contact.

We hope that other professionals will find in it an appropriate model or inspiration for further efforts in this area. For us as on-site administrators, French Practicum is a source of deep personal satisfaction. It is a pleasure to offer the willing and curious a liberating structure for their experience. The course is highly structured, yes, but it is also liberating because true freedom for the student abroad lies in connection. Opening doors towards encounters with the other and the self, the series of temporary restraints and commitments that is French Practicum paradoxically frees students through the true connection of authentic cultural experience.

\section{A P PENDIX}

\section{FRENCH PRACTICUM}

A Required Core Course

Goals:

Abundant, high-quality cultural experience; 
Thoughtful reflection upon that experience

Organization:

Six hours per week of experiential requirements

Personal writing and two hours weekly in class

\section{Academic Credit:}

Two credit hours recommended; pass/fail

Three-credit option available

\section{A) Experiential Requirements}

Three Components

1) Linguistic: weekly conversation exchange with French learner of English

2) Personal Interest: personal interest, hobby; membership in club, team; lessons, etc.

3) Community Service: two hours weekly of local volunteer work

B) Reflection and Analysis

Two Components

1) Personal Writing: weekly written report on experiential requirements, university experience, etc.; assembly of cultural information; personal analysis of chosen aspects of cultural difference

2) Weekly Classroom Session: continuing orientation, analysis, articulation 
Frontiers: The Interdisciplinary Journal of Study Abroad 